\title{
Gaucho, atlético y nacional. Imágenes de la famosa pelea del siglo $\mathrm{XX}^{1}$
}

\section{Gaucho, athletic and national. Images of the famous fight of the 2oth Century}

\author{
Antonella Bertolotto \\ Universidad Nacional de La Plata \\ Argentina \\ https://orcid.org/0000-0002-1356-7589
}

DOI: https://doi.org/10.25032/crh.v7i12.6

Recibido: $25 / 3 / 2021$

Aceptado: $18 / 5 / 2021$

Resumen. Se analizará la famosa pelea de boxeo entre Luis Ángel Firpo y Jack Dempsey realizada el 14 de setiembre de 1923 en el Polo Ground de Nueva York, Estados Unidos, a partir del análisis de las imágenes y los aportes de la historia social y cultural. Se indagará una amplia variedad de fuentes primarias, especialmente la prensa escrita argentina, focalizando en la función que tuvieron las imágenes para construir y transmitir ciertos sentidos e imaginarios, potenciando muchas veces los ya puestos en circulación a través de la escritura. La hipótesis afirma que la prensa escrita, a partir de uno de los eventos deportivos más importantes de la década del '20, utilizó las imágenes como práctica para lograr producir, representar y potenciar ciertos sentidos e imaginarios sobre la masculinidad y la nacionalidad argentina y, en menor medida, estadounidense.

Palabras clave: Boxeo, imágenes, masculinidad, nacionalidad

\footnotetext{
Abstract. The famous boxing match between Luis Ángel Firpo and Jack Dempsey which took place in September 14, 1923 at the Polo Ground in New York, United States, will be analyzed based on the analysis of the images and the contributions of social and cultural history. A wide variety of primary sources will be investigated, especially the

${ }^{1}$ Este trabajo es parte de un proyecto de investigación aceptado en las Becas al Estimulo Científico del Consejo Interuniversitario Nacional (EVC-CIN), titulado La pelea del siglo XX y la prensa escrita argentina en los años '20. Discursos, sentidos y tópicos en torno a la masculinidad, moral sexual, nacionalidad y latinidad, dirigido por el Dr. Pablo Ariel Scharagrodsky y como codirector el Dr. Alejo Levoratti.
} 
Argentine written press, focusing on the function that the images had to construct and transmit certain senses and imaginaries, often enhancing those already put into circulation through writing. The hypothesis affirms that the written press, starting with one of the most important sporting events of the 1920s, used images as a practice to produce, represent and enhance certain senses and imaginaries about Argentine masculinity and nationality and, to a lesser extent, the American.

Keywords: Boxing, Images, Masculinity, Nationality

\section{Introducción}

Partimos de entender a la prensa escrita como un actor social, político y pedagógico, como un espacio donde confluyen distintos contenidos e intereses posibilitando un espacio de producción cultural y una fuente de información histórica (Kircher 2005; Qués 2013; Bontempo 2012; De Diego 2006; Delgado y Rogers 2016; Delgado, Mailhe y Rogers 2014). Que pone en producción, transmisión, circulación y apropiación, en un determinado tiempo y espacio, ciertos discursos, sentidos y tópicos.

En este caso en particular se hará un análisis crítico de las imágenes que fueron puestas en producción, circulación, transmisión y apropiación a partir de la famosa «pelea del siglo», la pelea de boxeo por el título mundial de los pesos pesados entre Luis Ángel Firpo, El Toro salvaje de las Pampas (1894-1960), y Jack Dempsey El asesino de Manassas (1895-1983), realizada el 14 de setiembre de 1923 en el Polo Ground de Nueva York, Estados Unidos y transmitida por Radio Nacional a Buenos Aires, Argentina. La técnica principal que se utilizó es el análisis de documentos históricos y para ello se indagó en una amplia variedad de fuentes primarias, especialmente la prensa escrita argentina durante los meses de agosto, setiembre y octubre de 1923. Es así que se focalizó en las funciones que tuvieron las imágenes como constructoras y trasmisoras de sentidos y representaciones. En este sentido, entendemos a la imagen con una fuerza performativa, un hacer y dejar ver performativo, que pugna entre lo visible e invisible, entre lo representable e irrepresentable (Arfuch, 2009). Si bien se analizaron los periódicos y revistas Última Hora, Caras y Caretas, Fray Mocho, La Época, Crítica, La Nación, La Prensa, The Standart, Buenos Aires Herald, El Argentino, El Día, La Vanguardia y La Razón, a lo 
largo de este escrito se hará mayor referencia a Caras y Caretas, Fray Mocho, La Época y Crítica. Este recorte y elección en el análisis de las fuentes primarias se debe a la gran importancia que tuvieron estos medios de comunicación en los primeros años de la década del veinte en Argentina (Saítta 1998) y a la utilización que estos tuvieron de las imágenes como mecanismo para lograr construir, potenciar y transmitir sentidos y representaciones identitarias, nacionales, sexogenéricas y morales.

Este evento deportivo se da en un contexto caracterizado por cambios sociales, económicos, culturales, políticos, jurídicos y sexuales (Sarlo 1988; Barrancos, Guy y Valobra 2014). Un contexto en el que entra en crisis el modelo periodístico del siglo XIX, que implicaba estar ligados a facciones políticas para inaugurarse un nuevo modelo caracterizado principalmente por ser independiente, autónomo y moderno en las técnicas y tecnologías utilizadas (Saítta 1998). Sin embargo, a partir de la década del 1900 la revista Caras y Caretas, y luego también Fray Mocho, ya denota otro estilo periodístico y de edición distintos al del siglo xIX. Los periódicos y revistas seleccionados para este análisis, al igual que los periódicos socialistas de la época (Guiamet 2016), lograron incorporar distintos mecanismos para ser más agiles y dinámicos y aumentaron así el número de sus lectores y sus ganancias económicas. Específicamente, dos de esos nuevos mecanismos han sido la utilización cada vez más frecuente de imágenes (Szir 2016; Guiamet 2016) y el uso de publicidades (Scharagrodsky 2020). Estas nuevas prácticas se volvieron necesarias para poder mantener económica e ideológicamente a los distintos periódicos y revistas, ya que al tener autonomía e independencia debían afrontar los costos económicos que implicaba la modernización. En este sentido, la utilización cada vez más frecuente de estas nuevas prácticas no solo implicaba cuestiones meramente económicas, sino que también, al provocar un aumento en el número de sus lectores, lograron masificar ciertos sentidos, representaciones y discursos, y no otros, en función de establecer determinada opinión pública.

Estos desarrollos e innovaciones en los medios de comunicación se enmarcaban en un contexto argentino y latinoamericano con fuertes preocupaciones en torno al porvenir de la raza, el stock biológico de la nación y a la prevención y la lucha contra enfermedades respiratorias como la tuberculosis, que tomaron centralidad en las políticas estatales y en los medios de comunicación como la radio y el periódico. De esta manera, los discursos médicos y eugenésicos de la época toman protagonismo y se 
vuelven científicamente necesarios, procurando controlar y sistematizar las normalidades somáticas y los usos del cuerpo, la utilización del tiempo y del espacio libre y productivo, las estéticas y sensibilidades corporales, las relaciones entre las personas y otros aspectos más de la vida pública y privada de la población (Nari 2004; Armus 2007; Miranda 2012), provocando una medicalización de la vida individual y poblacional. En este sentido, gracias al gran desarrollo, a la expansión y la profesionalización de los medios de comunicación (Sarlo 1988; Saítta 1998; Bontempo 2012; Rocchi 2016), así como a la expansión de algunas prácticas deportivas como el fútbol, boxeo, turf, polo y atletismo, que permitieron la paulatina incorporación del país a un sistema internacional de competencias (Alabarces 2002; Archetti 2001 y 2005), los deportes en general, y el boxeo en particular, brindaron un nuevo espacio público de espectáculo y de consumo. Un nuevo espacio para la libre producción, transmisión y circulación de somatotipos y morfologías corporales, gestos, conductas, hábitos y sensibilidades que reforzaron y modelaron cierta estética en los cuerpos masculinos y femeninos, desarrollando una masculinidad moderna (Mosse 1998) y hegemónica (Bourdieu 2000), y construyendo consecuentemente una otredad. A su vez, este nuevo espacio posibilitó el despliegue de narrativas heroicas y caballerescas que delimitaban lo propio y ajeno, y lo nacional y lo extranjero (Alabarces 2002; Archetti 2001 y 2005). Debido a esto, y como uno de los eventos deportivos más importantes de la década del veinte, caracterizado por medios nacionales e internacionales como la pelea del siglo, se indagará como excusa para entender las lógicas nacionales, identitarias, morales y sexogenéricas.

\section{A través de la imagen}

Los periódicos y revistas Caras y Caretas (1898-actualidad), Fray Mocho (19131932), La Época (1915-1983) y Crítica (1913-1941) utilizaron imágenes, comprendiendo dentro de estas dibujos, fotografías y caricaturas, para transmitir y potenciar los sentidos y las representaciones en torno a la masculinidad popular, la nacionalidad argentina y la raza latina, en contraposición a la masculinidad, la nacionalidad estadounidense y la raza sajona.

En primer lugar, Caras y Caretas, fundada en 1898 por Eustaquio Pellicer y dirigida por José Sixto Álvarez, fue un seminario popular ilustrado, festivo, literario artístico y de actualidad con características misceláneas y con una periodicidad 
semanal. Marcó la historia del periodismo en Argentina, ya que logró incorporar nuevas tecnologías, especialmente las necesarias para la inclusión de las imágenes en el seminario, inaugurando un nuevo régimen de lectura que conjugaba lo verbal con lo icónico. Una revista que tuvo gran éxito debido a su precio accesible, a su formato manuable, a su temprana modernización e incorporación de imágenes y publicidades, a la presencia de cotidianidad urbana y al cruce de lo artístico con el humor descarado (Rogers 2008; Bontempo 2012; Szir 2016). Un espacio donde la «cultura plebeya transgredió los dispositivos de la cultura oficial, en una fórmula que conjugó la lectura con la vida urbana y el entretenimiento» (Bontempo 68). En segundo lugar, Fray Mocho fue una revista semanal que aparecía los viernes fundada en 1913 por Carlos Correa Luna (exdirector de Caras y Caretas), José Cao (reconocido dibujante) y Luis Pardo (escritor costumbrista que aparecía con el seudónimo de José García), entre muchos otros profesionales reconocidos que eran parte del staff de Caras y Caretas. El distanciamiento con Caras y Caretas surgió por «un conflicto originado aparentemente en su disconformidad con la línea editorial de esa revista» (Shirkin 132). A pesar de esto, siguió los mismos caminos en cuanto a la incorporación exitosa de las imágenes en sus páginas. En tercer lugar, el periódico La Época, fundado en 1916, tuvo una línea editorial muy relacionada con las propuestas de Hipólito Irigoyen. Por último, Crítica, fundado en 1913 por el uruguayo Natalio Botana, se caracterizó por ser un periódico comercial con tono sensacionalista, irónico, coloquial y humorístico, con grandes titulares e imágenes.

La práctica del uso de las imágenes como mecanismo constructor, potenciador y transmisor de sentidos y representaciones no era azarosa, sino que estaba en sintonía con las notas de estos medios de comunicación y lograba conjugar de manera exitosa el lenguaje verbal con el icónico. De esta manera, las imágenes acompañaban, llenaban y reforzaban lo escrito en las notas periodísticas, lo que daba mayor sentido y representatividad a los sentidos construidos a transmitir. ${ }^{2}$ A partir de la pelea del siglo los medios de comunicación nacionales e internacionales (Estados unidos, México, Chile, Uruguay, Perú, Europa, etc.) supieron desplegar distintas lógicas identitariasmorales y sexogenéricas tanto nacionales como extranjeras a través de la práctica del boxeo, pero más precisamente a través de la figura de Firpo y de Dempsey. Destinaban

\footnotetext{
${ }^{2}$ Un aspecto destacable es que paulatinamente a lo largo de estos años nuevos sectores de la población comenzaban a acceder a la cultura letrada, por lo que el lenguaje icónico era mejor comprendido que el verbal.
} 
notas escritas, cartas de los lectores y las lectoras, mensajes de y hacia Firpo y Dempsey, competencias de dibujos, apuestas, publicidades, fotografías, dibujos y caricaturas para llenar de sentidos las figuras de ambos boxeadores (Bertolotto 2020; Scharagrodsky 2021). Lógicas y narrativas que no eran totalmente homogéneas y generales, debido a que los distintos periódicos y revistas no estaban dirigidos hacia los mismos sectores de la población argentina. Por ejemplo, el periódico socialista $L a$ Vanguardia fue el medio de comunicación con mayor disconformidad y crítica hacia la práctica del boxeo. 3 Otros periódicos como The Standard, Buenos Aires Herald y La Prensa tenían un discurso más informativo y neutral con respecto al match y a la figura de los boxeadores. Sin embargo, Caras y Caretas, Fray Mocho, La Época y Crítica mostraron a Firpo como un ideal físico, ${ }^{4}$ mental y moral, como un héroe e ídolo nacional y, en consecuencia, como un gran representante de la raza latina. 5

Este acontecimiento deportivo, principalmente durante mediados de agosto hasta fines de setiembre, fue la noticia más importarte en los medios de comunicación nacionales. Se utilizaron imágenes de todos los tamaños, ocupando solo una parte o directamente toda la página, ubicadas en la tapa o en cualquier otro lugar del periódico o revista, ya que su ubicación no se limitaba a la sección deportiva. Imágenes que tampoco se limitaron a los medios de comunicación nacionales, sino que también fueron tapas de periódicos internacionales (Scharagrodsky 2021).

\footnotetext{
${ }^{3}$ «El resultado de esta sugestión multiplicada al infinito, es que muchos ciudadanos ingenuos, acaso más de lo que suponemos esperen la solución del combate como signo trascendental desde el punto de vista de la nacionalidad, la raza, y no sabemos cuántas cosas más, sin detenerse a reflexionar que son víctimas inconscientes de una superchería de las más burdas. No hemos de repetir aquí las razones que nos mueven a combatir al pugilismo por dinero como uno de los aspectos más repugnantes del deporte, cuyo fin viene desnaturalizando hasta el absurdo» (La Vanguardia [Buenos Aires], set. 13, 1923: 1); «Desde que comenzó a cundir en nuestro país la propaganda alrededor del nombre de Firpo, haciendo de sus encuentros pugilísticos algo así como una cuestión de orgullo y supremacía nacionales, como si de la fuerza de sus puños pudiese depender el destino o el buen nombre del país en el mundo, manifestamos sin rodeos nuestro más decidido repudio por esa clase de exageraciones morbosas» (La Vanguardia [Buenos Aires], set. 15, 1923: 1).

${ }^{4}$ «Firpo ha sido una muestra sacada del inmenso stock, de hombres fuertes, valientes y corajudos, que posee la Argentina. Fue una muestra bien presentada y de óptima calidad que hace pensar en el grueso de la partida» (Crítica [Buenos Aires], set. 7, 1923: 14).

5 «Homenaje de reconocimiento a quien ha prestigiado así, en la propia capital del deporte universal, el nombre argentino, y ha hablado al mundo en el lenguaje categórico del ring, de una raza de hombres fuertes, valientes y caballeresco» (Crítica [Buenos Aires], set. 15, 1923: 1).
} 


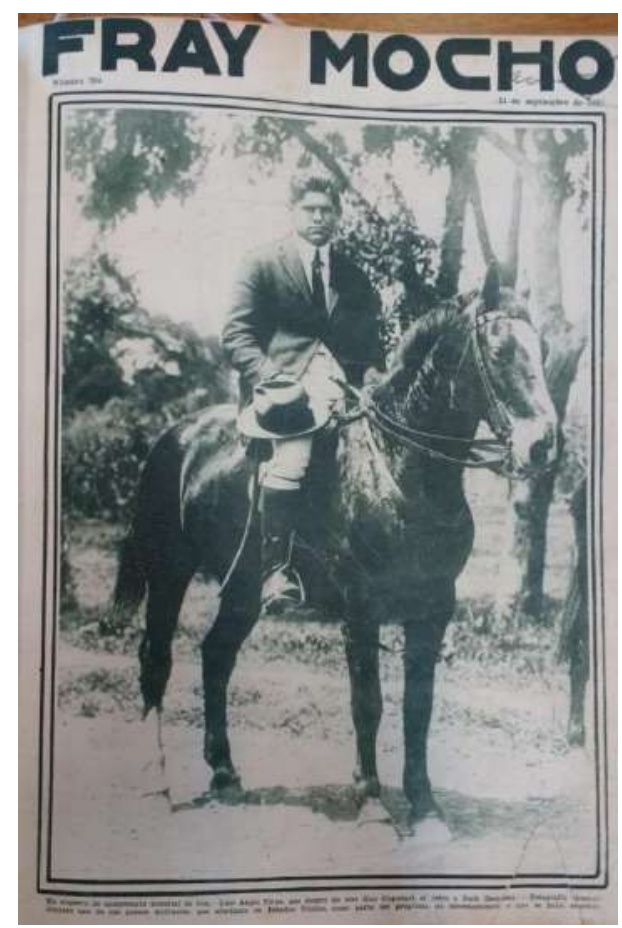

Imagen 1. Fray Mocho [Buenos Aires], set. 11, 1923: 596, Carlos Correa Luna

Esta fotografía (Imagen 1) fue la tapa de Fray Mocho el 11 de setiembre de 1923 con un pequeño texto acompañándola. ${ }^{6}$ Dicha fotografía fue obtenida, y no de manera casual, durante uno de los paseos matinales de Firpo en los Estados Unidos como parte de su programa de entrenamiento. La postura, el peinado, su mirada y vestimenta, el paisaje que hay detrás, el caballo, la forma en que lo está montando y la posición de la cámara fueron elegidos antes. Vestido de traje, con botas para montar, con sombrero y arriba del caballo era como Firpo hacía sus paseos por la ciudad, siendo fiel a sus costumbres nacionales.

En este sentido, una fotografía se construye. Permite construir ciertas miradas del mundo al generar diversos discursos visuales, operando de esta manera como una práctica de significación (Bonetto, 2016). Lo que la cámara ve y deja ver es un reflejo de una mirada subjetiva que muchas veces intenta ser objetiva. De esta manera, las imágenes y en particular las fotografías nos permiten analizar, observar y teorizar acontecimientos históricos. Por lo tanto, al analizarlas se puede inferir que reiteradas veces en las fotografías y en las descripciones que las acompañan se hacen alusiones a las características criollas de Firpo. En este sentido, se denota una preocupación por

\footnotetext{
${ }^{6}$ «En vísperas del campeonato mundial de box.- Luis Ángel Firpo, que dentro de tres días disputará el cetro a Jack Dempsey.- Fotografía obtenida durante uno de sus paseos matinales, que efectuara en Estados Unidos, como parte del programa de entrenamiento a que se halla sometido» (Fray Mocho [Buenos Aires], set. 11, 1923: 594, Carlos Correa Luna).
} 
parte de algunos de los medios de comunicación argentinos de transmitir que Firpo, a pesar de estar en los Estados Unidos, «sigue tan criollo como siempre».7

Otro de los aspectos analizados es la incesante intención de trasmitir la vida del ídolo nacional en su estadía en los Estados Unidos. Había una necesidad por transmitirlo todo. Sus entrenamientos, descansos, salidas, paseos, comidas, visitas, compañías femeninas, amigos y también sus estados de ánimo. Todo debía ser informado, narrado, comentado y mostrado por la prensa escrita.

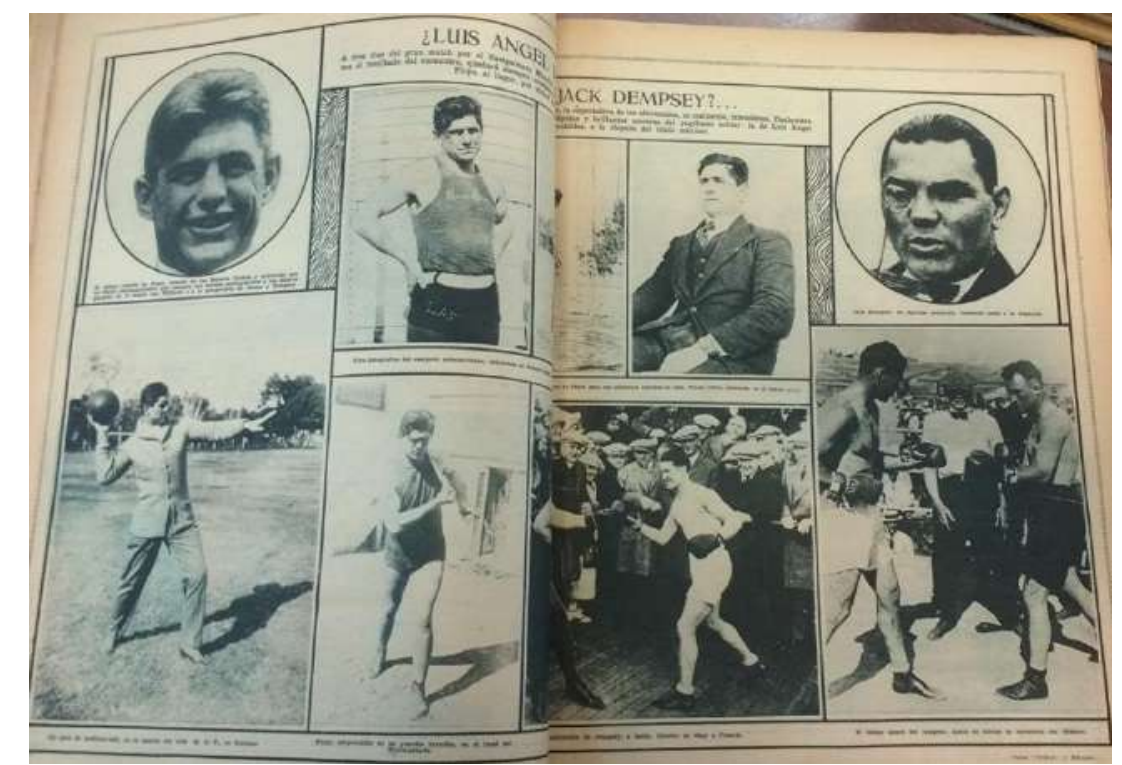

Imagen 2. Fray Mocho [Buenos Aires], set. 11, 1923: 594, Carlos Correa Luna

Este conjunto de fotografías bajo el título de «Luis Ángel Firpo o Jack Dempsey» (Imagen 2) ocupa dos páginas de la revista. En ellas se lo muestra a Firpo en todas sus facetas: alegre y contento, pero a la vez serio y pensativo, así como también sentado y entrenando, concentrado en el futuro match por el título mundial de los pesos pesados, vestido de traje y con ropa deportiva, con vista a la cámara, hacia arriba y hacia abajo. En cuanto a la cantidad de las fotografías de Dempsey en esta revista y en las demás fuentes históricas analizadas, esta es menor en comparación con la cantidad de fotografías dedicadas a Firpo. Contrariamente al ídolo argentino, el boxeador norteamericano es representado como un exitoso, elegante y científico boxeador, pero a su vez tramposo y ventajero. A lo largo de las páginas se lo muestra haciéndole culto a la elegancia, realizando actividades en sus momentos de descanso, haciendo su

\footnotetext{
${ }^{7}$ Crítica [Buenos Aires], set. 7, 1923: 14.
} 
«vuelo planeado» 8 fuera del ring (Imagen 3 ), fatigado y cansado por los golpes de Firpo.

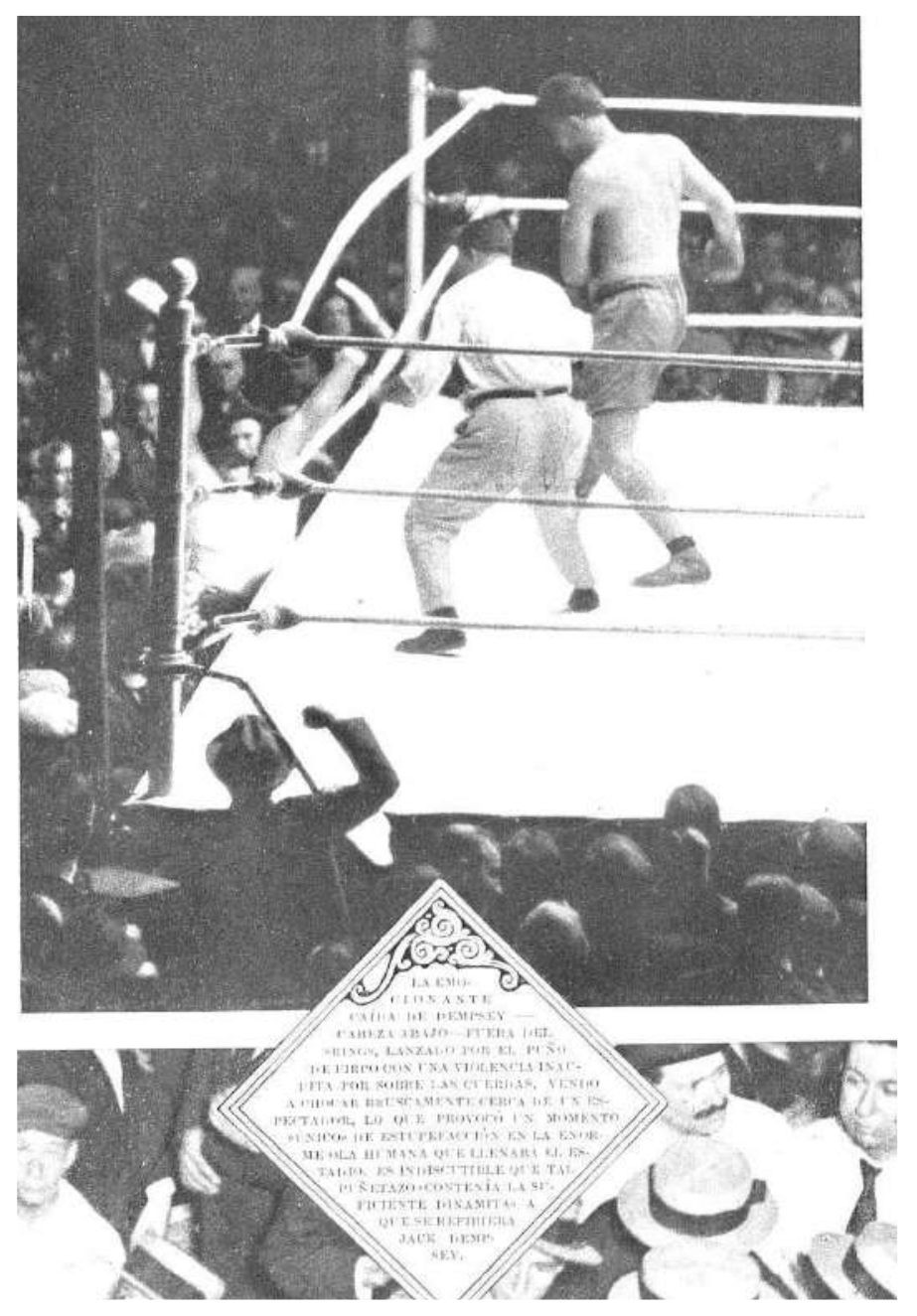

Imagen 3. Caras y Caretas [Buenos Aires], oct. 13, 1923: 1306, José S. Álvarez9

\section{Fuerte, viril y atlético. La representación del ídolo nacional}

Como ya hemos dicho, esta pelea de boxeo fue uno de los acontecimientos deportivos más importantes de la década del veinte, recordada como la pelea del siglo solamente tuvo una duración de tan solo 3 minutos y 57 segundos. Fue la primera y más grande transmisión de un acontecimiento deportivo por radio nacional desde el Polo Grounds en Nueva York, Estados Unidos hacia Buenos Aires, Argentina; fue la

\footnotetext{
${ }^{8}$ «El formidable "vuelo planeado" del campeón mundial, que lanzado violentamente fuera del ring, va a caer donde están los periodistas» (Fray Mocho [Buenos Aires], oct. 9, 1923: 598, Carlos Correa Luna).

${ }^{9}$ «La emocionante caída de Dempsey — cabeza abajo - fuera del "ring", lanzado por el puño de Firpo con una violencia inaudita por sobre las cuerdas, yendo a chocar bruscamente cerca de un espectador, lo que provocó un momento "único" de estupefacción en la enorme ola humana que llenaba el estadio, es indiscutible que tal puñetazo "contenía la suficiente dinamita" a que se refiriera Jack Dempsey».
} 
primera pelea de boxeo por el título mundial entre un argentino y un estadounidense; fue la primera vez que un deportista argentino estaba en las tapas de revistas y periódicos internacionales; por ser una pelea millonaria (solo los tickets vendidos superaron el millón de dólares);10 por la gran expectativa y exaltación nacional e internacional (Scharagrodsky 2021; Bertolotto 2020). La gente se reunía en las calles, en avenidas principales, en las sedes periodísticas, en bares, salones y clubs. Emociones y sentimientos que no se habían visto antes en la historia, ya que toda América Latina y el mundo entero estaban expectantes de la resolución de la pelea. ${ }^{11}$

Alabarces (2002) plantea que en la década del veinte se pone en marcha, a partir del fútbol como máquina cultural, el proceso de construcción del primer nacionalismo deportivo, para lo cual es necesario que se den una serie de aspectos. Si bien él hace referencia al fútbol, es posible pensarlo a partir de la práctica del boxeo. Estos aspectos o momentos implican un rito de pasaje deportivo, en este caso de un boxeo europeo a un boxeo argentino y criollo, que se dio con la llegada de los inmigrantes europeos al puerto de Buenos Aires (Palla 2018); se necesita del éxito deportivo para poder sostener la representatividad nacional, por esto la imperiosa necesidad de que Firpo obtuviera el título mundial de los pesos pesados; se necesitan héroes fundadores que garanticen cierta legitimidad de la práctica; y se necesita un estilo diferenciado de la práctica, en este caso el característico estilo criollo de Firpo. Si bien en Argentina el fútbol tuvo mayor expansión, desarrollo y popularización que el boxeo, es posible pensar que a partir de este acontecimiento deportivo se intentó poner en marcha la construcción de uno de los primeros nacionalismos deportivos que, sin embargo, fue invisibilizado por otras prácticas deportivas, como puede ser el caso del fútbol, debido a cuestiones sociales, políticas, económicas y culturales que exceden a las prácticas deportivas.

A partir de la hipótesis de Alabarces (2002), y teniendo en cuenta el insipiente campo deportivo de la Argentina y más que nada del boxeo, Firpo no solo era la promesa y a su vez demostración del buen desarrollo del boxeo argentino, con un estilo propio y característico, como lo intento ser el estilo criollo. Sino que también era la garantía y demostración del desarrollo físico (Imagen 4), intelectual y moral de los

\footnotetext{
10 «La recaudación pasó de la suma de 1.250 .000 dólares $— 85.000$ personas en el estadio y 25.000 fuera $\longrightarrow$ (Crítica [Buenos Aires], oct. 4, 1923: 1).

11 «Toda América Latina está con Luis A. Firpo» (Crítica [Buenos Aires], set.13, 1923: 1).
} 
hombres que poblaban la Argentina. En este sentido, Mosse (1998) plantea que la construcción de la masculinidad moderna depende de la relación entre alma, cuerpo, moralidad y estructura corporal, una relación que pretende ser natural para volverse estándar de la normalidad, procurando construir patrones normativos de moralidad y comportamiento. Así, la masculinidad tiene que ser cultivada y desarrollada con constancia, implica un cultivo corporal y moral a través de distintos hábitos y conductas socialmente establecidas como sanas y masculinas. Uno de los vehículos más utilizados y eficaces para instalar como hegemónicas ciertas masculinidades, y como saludables en términos físicos, intelectuales y morales ciertas conductas, fueron las prácticas deportivas. A lo largo del siglo Xx, principalmente en sus comienzos, los deportes estuvieron bajo la legitimidad de las ciencias médicas y fisiológicas, convirtiéndose así en un bien necesario para el mejoramiento y desarrollo de las aptitudes físicas, intelectuales y morales de los cuerpos individuales y poblacionales.

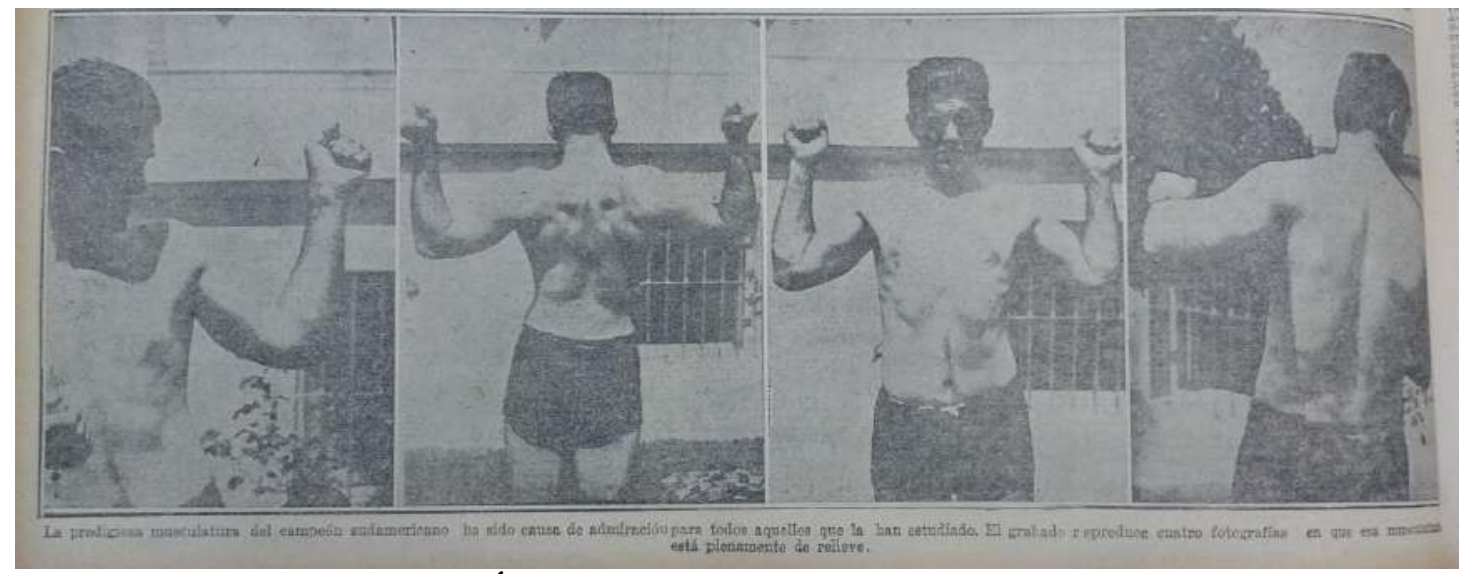

Imagen 4. La Época [Buenos Aires], set. 14, 1923: 2012

Firpo era un símbolo de nacionalidad y masculinidad popular argentina, era considerado por ciertos medios de comunicación como «una figura nacional; todo un símbolo en nuestro joven escenario deportivo; un ídolo de las multitudes».13 Un aspecto no menor a destacar es que el boxeo como espectáculo público y rentado estaba considerado como ilegal en la Argentina. Solo estaba permitido en algunos municipios de la provincia de Buenos Aires como Avellaneda, la zona del Mercado Central, Barracas y Lomas de Zamora. ${ }^{14}$ A pesar de esto, su supuesta victoria lo pondría en lo

\footnotetext{
12 «La prodigiosa musculatura del campeón sudamericano ha sido causa de admiración para todos aquellos que la han estudiado. El grabado reproduce cuatro fotografías en que esa musculatura está plenamente de relieve».

${ }^{13}$ Crítica [Buenos Aires], set. 11, 1923: 3.

${ }^{14}$ En caso de querer llevar a cabo un espectáculo público de boxeo en otros municipios, era necesario solicitar un permiso a las autoridades pertinentes del municipio. En caso de ser negada la autorización, o de no haberla pedido,
} 
más alto de los laureles deportivos, ${ }^{15}$ posicionándolo como un héroe, legitimador y garante de la práctica y los sentidos que confluían en ella.

Una de las notas del periódico La Época, que pertenecía a la sección especial de 20 páginas, publicada el mismo día en que se hizo la pelea, ocupó casi la totalidad de una página con la fotografía del rostro de Luis Ángel Firpo. Esta fotografía estaba bajo el título de «El hombre que tiene en sus manos el prestigio pugilísticos de la Argentina» (Imagen 5), con un pequeño texto debajo. ${ }^{16}$

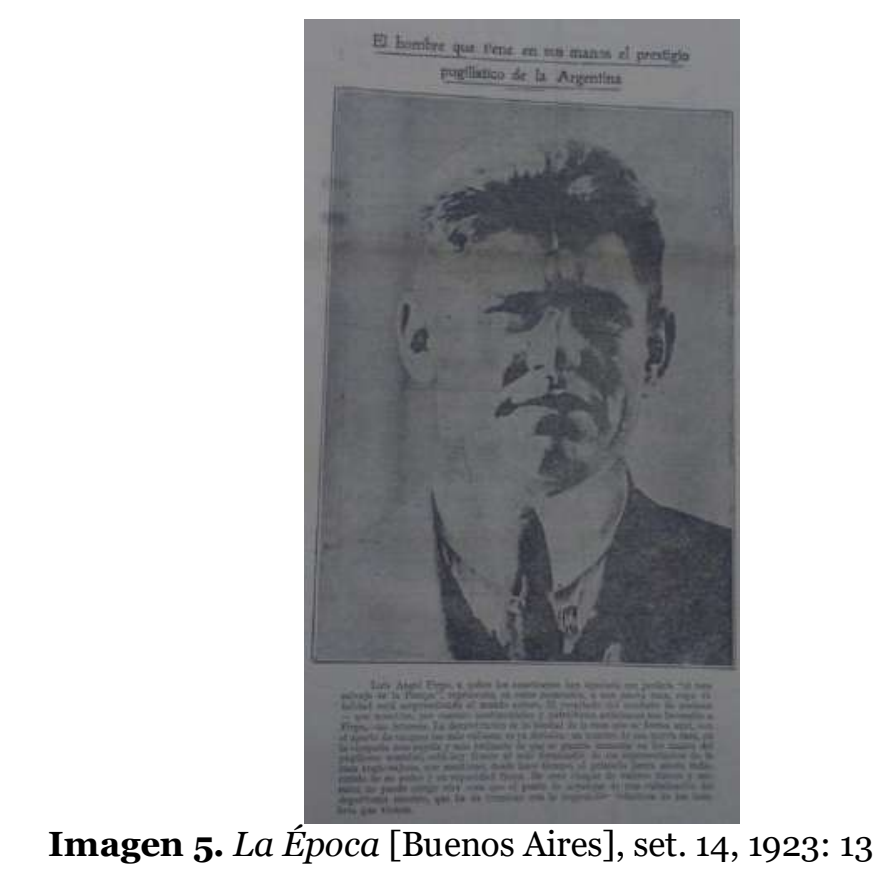

Esta fotografía y las demás que se encontraba a lo largo de la sección especial del periódico dan cuenta de la importancia y trascendencia que cobraría este match. El devenir del deporte, los sentimientos nacionales y patrióticos y las características

el espectáculo no podría llevarse a cabo. Sin embargo, muchas veces se realizaban ilícitamente, contando con la ayuda de las fuerzas policiales y el cuerpo de inspectores del municipio.

15 «El match mundial permitirá afianzar el bizarro deporte consolidándose en las costumbres y provocando la sanción definitiva de las ordenanzas que reglamentarán entre nosotros el box libre. Así se contribuirá al mejoramiento de la raza, a la fortaleza del carácter, desarrollando la firmeza y la voluntad, condiciones indispensables al desarrollo y el progreso de toda democracia bien organizada» (La Época [Buenos Aires], set. 14, 1923: 17).

16 «Luis Ángel Firpo, a quien los americanos han apodado con justicia "el toro salvaje de la Pampa”, representa, en estos momentos, a una nueva raza, cuya vitalidad está sorprendiendo al mundo entero. El resultado del combate de mañana —que nosotros, por razones sentimentales y patrióticas, anhelamos sea favorable a Firpo — no interesa. La demostración de la bondad de la raza que se forma aquí, con el aporte de sangres las más valiosas, es ya decisiva: un hombre de esa nueva raza, en la campaña más rápida y más brillante de que se guarde memoria en los anales del puglismo mundial, está hoy frente al más formidable de los representantes de la raza anglo-sajona, que mantiene, desde hace tiempo, el primado hasta ahora indiscutido de su poder y su capacidad física. De este choque de valores físicos y morales, no puede surgir otra cosa que el punto de arranque de una culminación del deportismo nuestro, que ha de terminar con la imposición definitiva de los hombres que vienen» (La Época [Buenos Aires], set.14, 1923: 13). 
físicas, intelectuales y morales de las razas estaban en disputa por imponerse una sobre la otra. En un contexto en el que los deportes eran vistos como formadores de cuerpos normativos para la sociedad y como la salvación y la corrección de todos los males sociales, culturales y genéticos, Firpo era el hombre que tenía en sus manos, específicamente en sus puños, el prestigio pugilístico y nacional de la Argentina y de toda la raza latina. ${ }^{17}$ Una raza que intentaba estar unida en forma fraternal entre todos los países latinoamericanos. ${ }^{18}$

En este sentido, lo muestran vestido de traje, comprometido, pensativo y con vista al frente como si estuviera mirando hacia el futuro, como el gran representante de la nación y del boxeo argentino. Por lo tanto, Firpo condensaba la bondad, caballerosidad, honradez, fortaleza, humildad, virilidad y vitalidad de la nueva nación, inaugurando de esta manera una nueva raza latina y el deportismo argentino. Una raza latina instintiva, ${ }^{19}$ pasional, indisciplinada, caballera, viril, atlética, fuerte, resistente, honrada y honesta, en contraposición a una raza sajona metódica, calculadora, científica, disciplinada, fuerte, resistente, atlética, mecánica, eficiente, fría y embustera, ${ }^{20}$ características que condensaban el deber ser, un ethos propio, de cierta masculinidad popular y nacionalidad argentina conformando así la latinidad, contraponiéndose al deber ser de cierta masculinidad y nacionalidad estadounidense que constituían las representaciones a la raza sajona.

\footnotetext{
17 «Nuestro país se impone como constitutivo por una raza fuerte y viril. Lo ha demostrado en todos los deportes, desde el heroísmo de nuestros aviadores hasta la resistencia de los nadadores y la destreza insuperable de los jinetes argentinos que en los campos de polo asombrara a ingleses y norteamericanos. La Republica argentina no es el país blandengue y dormilón que se suponía antes entre los europeos confundiendo en un denominador común a todos los países de la despreciada "South América". Se está formando aquí una raza pujante y dominadora, Firpo no es un caso aislado, una excepción dentro del conjunto del país. Es un representativo, el mejor de los suyos, en el más viril y recio de los deportes. Su destreza criolla, que no es ciencia aprendida sino intuición [...] los colores de la enseña patria se alzarán triunfadores una vez más» (La Época [Buenos Aires], set. 14, 1923: 17).

18 «Chilenos, uruguayos, paraguayos no hacen cuestión de nacionalidades. Para ellos Firpo no pertenece a la Argentina. Firpo es sudamericano, es chileno, boliviano, uruguayo, paraguayo y argentino. La pelea sensacional de esta noche ha tenido la virtud de trastocar nuestras costumbres, modificar nuestras modalidades idiosincrásica, poner, en fin, una nota de simpático entusiasmo donde todo era especulación, movimiento material, ambición y ruido» (Crítica [Buenos Aires], set. 14, 1923: 6).

19 «Firpo se sujeta muy poco de la escuela, boxea instintivamente pero al extremo de anular la experiencia. Lleva en sus puños un anhelo de triunfo sin acordarse de que puede ser vencido, es fuerte, impetuoso, arrollador, insensible al castigo, coloca el puñetazo con efectos terribles e inmediatos» (Crítica [Buenos Aires], set. 12, 1923: 2).

${ }^{20}$ «Dempsey es el boxeador científico y disciplinado por excelencia. Se lo puede considerar una máquina de boxear, que obedece a la dirección de Kearnas [...] Firpo, en cambio, es el boxeador por instinto. Indisciplinado y hasta caprichoso, no se somete a reglas y rechaza todo lo que vaya contra su libre albedrio» (Crítica [Buenos Aires], set. 11, 1923: 3); «Dempsey, boxeador de escuela; lo acompaña el optimismo y la confianza que le da su encumbramiento; es frio, calculador, recio, fuerte pegador» (Crítica [Buenos Aires], set. 12, 1923: 2).
} 


\section{Crítica: Boxeo, imagen y humor}

El periódico Crítica, durante los primeros años de la década del veinte, estaba en pleno cambio, desarrollo y expansión para disputar el campo hegemónico del mercado editorial, que estaba en manos de La Prensa y La Nación. Precisamente pretendía conquistar el espacio de la tarde, en manos de La Razón (Saítta 1998; Bontempo 2012). A partir de abril de 1923, Crítica se autodenominó la «voz del pueblo» (Saítta 1998), representante de la voz popular, caracterizado también por ser un «periódico social» (Bontempo 67), en defensa constante de los intereses populares, con permanentes ofertas y brindando nuevos servicios a sus lectores. En este sentido, y por considerar al boxeo como un deporte popular relacionado con sectores de la población baja o media de Argentina, fue el periódico con mayor cobertura sobre el match. En los meses previos, durante la pelea y en los meses posteriores desplegaron amplias notas con respecto al espectáculo deportivo, desde las primeras hasta las últimas páginas, notas que narraban los entrenamientos de los boxeadores, su alimentación, paseos, contexturas físicas, atributos morales e intelectuales, opiniones de deportistas, exdeportistas, famosos/as, entrenadores, exentrenadores y del público en general. A través de las distintas secciones dedicadas a la pelea del siglo, desplegaron una lógica discursiva e iconografía coloquial, irónica, humorística y sensacionalista, logrando condensar una serie de discursos, sentidos y representaciones en torno a la sexualidad, a la moral y a la nacionalidad argentina y, en menor medida, estadounidense.

Una de las secciones o mecanismos más utilizados por el periódico fueron las famosas caricaturas realizadas por el Mono Taborda, también tituladas «Hípicas»,21 «Firpisticas»,22 «iFirpo, sí! iDempsey, no!»,23 «Cosas del Mundo»,24 «Comentarios de un firpista» 25 o simplemente con títulos sensacionalistas como «Firpo en Martín Fierro» (Imagen 6), «Lo llevan al sacrificio», ${ }^{26}$ «iLas inquietudes del Tío Sam!»,27 Además del Mono Taborda estaban como caricaturistas los señores Rojas, Blay, Pardagnol y Oñiverra, quienes tenían un papel menor en el periódico. Por lo tanto,

\footnotetext{
${ }^{21}$ Crítica [Buenos Aires], set. 1, 1923: 14.

${ }^{22}$ Crítica [Buenos Aires], set. 1, 1923: 3.

${ }^{23}$ Crítica [Buenos Aires], set. 4, 1923: 7.

${ }^{24}$ Crítica [Buenos Aires], jul. 16, 1923: 1.

${ }^{25}$ Crítica [Buenos Aires], jul. 13, 1923: 3.

${ }^{26}$ Crítica [Buenos Aires], jul. 25, 1923: 8.

${ }^{27}$ Crítica [Buenos Aires], ago. 30, 1923: 5.
} 
debido al fuerte protagonismo del Mono Taborda como caricaturista en Crítica, este escrito se centrará en el análisis de sus caricaturas.

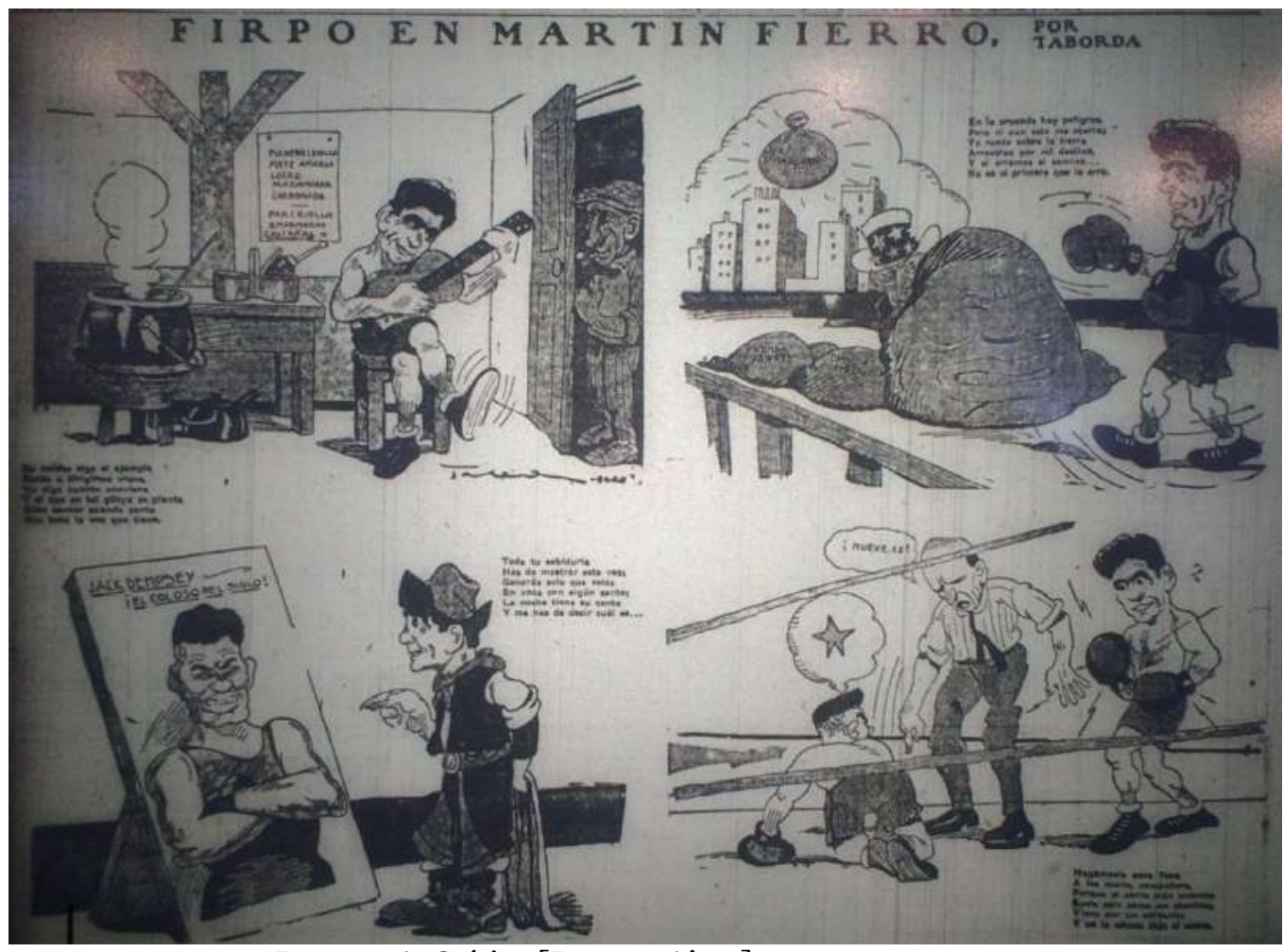

Imagen 6. Crítica [Buenos Aires], set. 13, 1923: 10

La caricatura bajo el título de «Firpo en Martín Fierro» está compuesta por cuatro viñetas, donde cada una de ellas tiene una estrofa del Martín Fierro. Lo muestran a Firpo de distintas maneras: tocando la guitarra, tomando mate, vestido como gaucho, boxeando, cocinando y con una lista de las comidas y bebidas típicas argentinas colgadas en la pared (puchero criollo, mate amargo, locro, mazamorra, carbonada, pan criollo, empanadas y castañas). Dichas conductas y gustos caracterizaban el estereotipo criollo-gaucho-argentino. Por otro lado, los otros dos actores que aparecen son Jack Dempsey el cual aparece tirado en el piso debido a los fuertes golpes de Firpo o dibujado en un cartel y el otro de los actores es el Tío Sam, un símbolo nacional de los Estados Unidos, caracterizado por sus intereses meramente económicos.

Otra de las caricaturas que condensa varios sentidos y representaciones en torno a la moral, la sexualidad y la nacionalidad argentina y estadounidense fue la caricatura de «Ya va a empezar la pelea» (Imagen 7). En la cual se lo muestra a Firpo con las vestimentas de un típico gaucho argentino, en una mano con una espada y en la otra con guantes de boxeo. Fuerte, aguerrido y audaz dispuesto a darlo todo por su nación. 
Por otro lado, el Tío Sam y Jack Dempsey están aterrorizados por la fuerza de las castañas criollas y la brutalidad del coloso de Firpo. A su vez, esta caricatura refleja la importancia que los medios de comunicación locales le daban a la pelea de boxeo, ya que intentaban transmitir que toda la atención del mundo estaba puesta en este evento deportivo, dejando de lado cualquier otro tipo de acontecimiento, hasta la revolución española que se estaba llevado a cabo en el continente europeo.

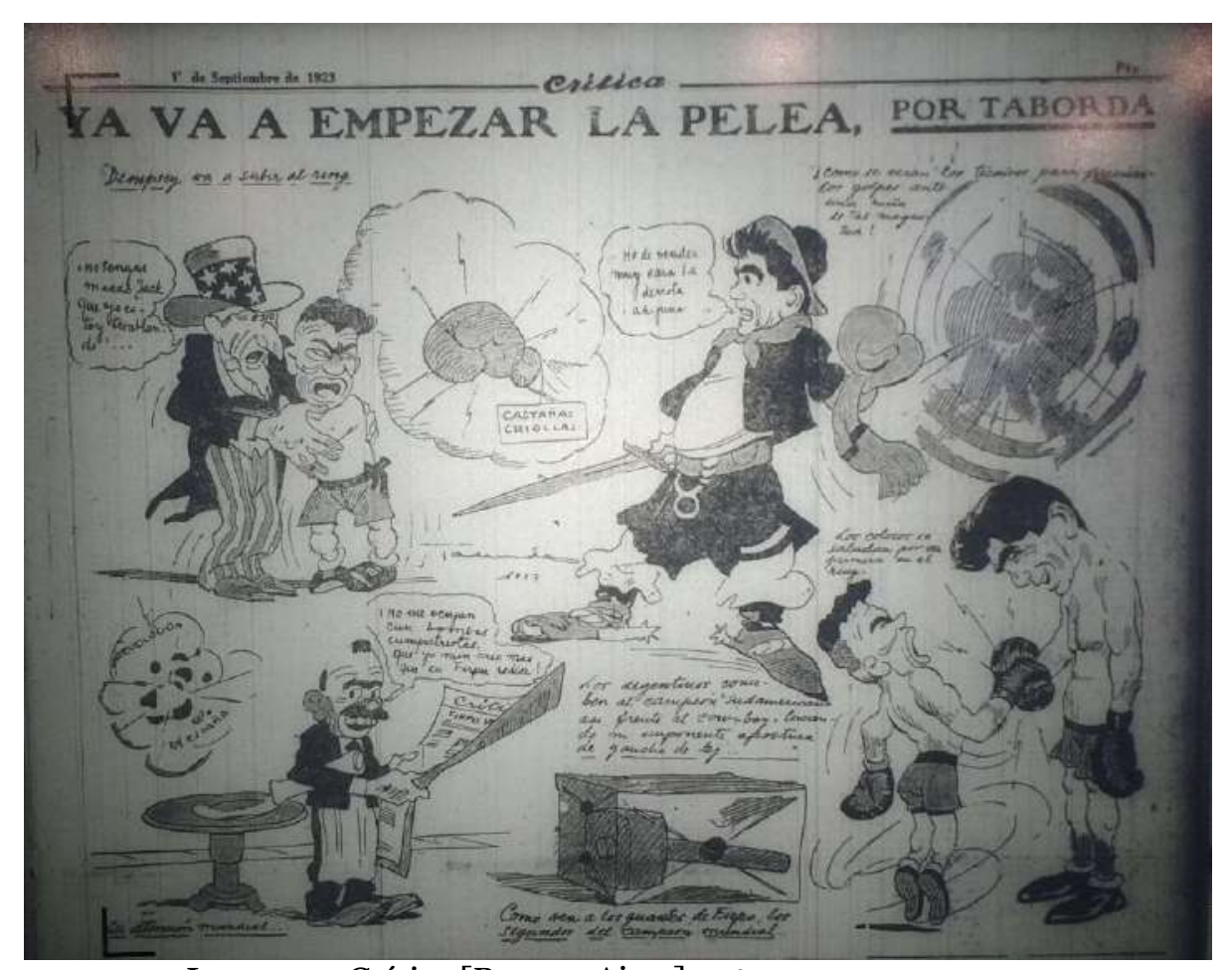

Imagen 7. Crítica [Buenos Aires], set. 14, 1923: 5

En este sentido, las caricaturas sirven como un canal más directo, ágil, sarcástico y entretenido para transmitir y potenciar ciertos sentidos constructores de un imaginario social o identidad nacional, un ideario que no era posible transmitir, con la misma efectividad, a través de las largas o cortas notas escritas periodísticas. Las caricaturas acompañaban las notas periodísticas escritas, potenciando, de forma grotesca, exagerada y humorística, los sentidos y representaciones en torno a cierta masculinidad y la nacionalidad argentina y a cierta masculinidad y nacionalidad estadounidense. En este sentido, en la mayoría de las caricaturas se lo muestra a Firpo como un auténtico representante del pueblo argentino, mostrando un hombre humilde, pero que por los engaños y trampas de los estadounidenses era muchas veces atraído por el dinero extranjero. ${ }^{28}$ Un hombre fuerte, resistente, atlético, viril,

${ }^{28}$ Crítica [Buenos Aires], jul. 13, 1923: 3; Crítica [Buenos Aires], set. 5, 1923: 10; Crítica [Buenos Aires], oct. 11, 1923: 2. 
caballero, noble, pasional y honrado. Se lo muestra escuchando tango, ${ }^{29}$ tomando mate amargo, comiendo mucha carne, carbonada, puchero, pan criollo, naranja, empanadas, vestido como gaucho y tocando la guitarra, ${ }^{30}$ características que reforzaban constantemente los ideales y representaciones acerca de la masculinidad popular y la tríada criollo-gaucho-argentino, ideales y representaciones que también reforzaban y construían el estereotipo de raza latina. En este sentido, según estos medios de comunicación, Firpo representaba a los hombres que poblaban una nueva nación en vías de desarrollo, con potencial, juventud, fuerza y honradez.

Estos estereotipos que intentaron ser normativos fueron contrapuestos, a lo largo de toda la cobertura de la pelea, a los sentidos y representaciones en torno a la masculinidad y nacionalidad estadounidense. Una masculinidad estadounidense fuerte, resistente, ingeniosa, fría, calculadora, astuta, disciplinada, ventajera, eficiente, viril y atlética, que representaba una nación con mayores desarrollos políticos, sociales y económicos que la Argentina. Características que fueron representadas por Jack Dempsey, Tex Rickard y el Tío Sam, tres actores tomados por la prensa escrita argentina para intentar reflejar un típico estereotipo estadounidense, el cual estaba vinculado con el aumento, a toda costa, de sus ganancias económicas a partir del espectáculo deportivo. Representando, en este sentido, el ideal yankee que constituía la raza sajona.

Firpo perdió. Según los medios de comunicación latinoamericanos su derrota podía deberse a varios aspectos: al cansancio acumulado y a la falta de descanso debido a la seguidilla de peleas organizadas por Tex Rickard, a la falta de experiencia y técnica del boxeo, a las malas actuaciones del árbitro local Johnny Gallagher, ya que no contó la totalidad del tiempo que Dempsey pasó fuera del ring después del fuerte derechazo de Firpo (contó 10 segundos de los 17 segundos que Dempsey estuvo fuera del ring) y debido a los cuatro fauls que no se le tuvieron en cuanta a Dempsey. Crítica, al igual que otros medios de comunicación, no pudo aceptar la derrota de Firpo, ${ }^{31}$ aspecto que

\footnotetext{
${ }^{29}$ Crítica [Buenos Aires], set. 9, 1923: 4.

${ }^{30}$ Crítica [Buenos Aires], set. 4, 1923: 7; Crítica [Buenos Aires], set. 5, 1923: 7; Crítica [Buenos Aires], set. 13, 1923: 10.

31 «Firpo, todo el bronce y ébano, la crencha hirsuta y bravía, impresionaba con su aspecto de gigante aborigen. Esos dos monstruos, forjados en lo más viril de dos razas, elaborados por la esencia y el arte de pegar, como dos trombas de la naturaleza. [...] Firpo ha caído con honra [...] Saludamos a Firpo caído con honor, las virtudes bravías de la raza. El gaucho que antaño tramontó los Andes como soldado y que hoy solo busca lances en las arenas olímpicas del estadio, cuando caía, si por azar caía, conservaba intacta su recia envergadura espiritual; más
} 
también fue reflejado en las caricaturas «No está muerto quien pelea» (Imagen 8), «¿่Ha sido una pelea o un asesinato alevoso?»,32 «iNo hay plazo que no se cumpla!»,33 entre otras más.

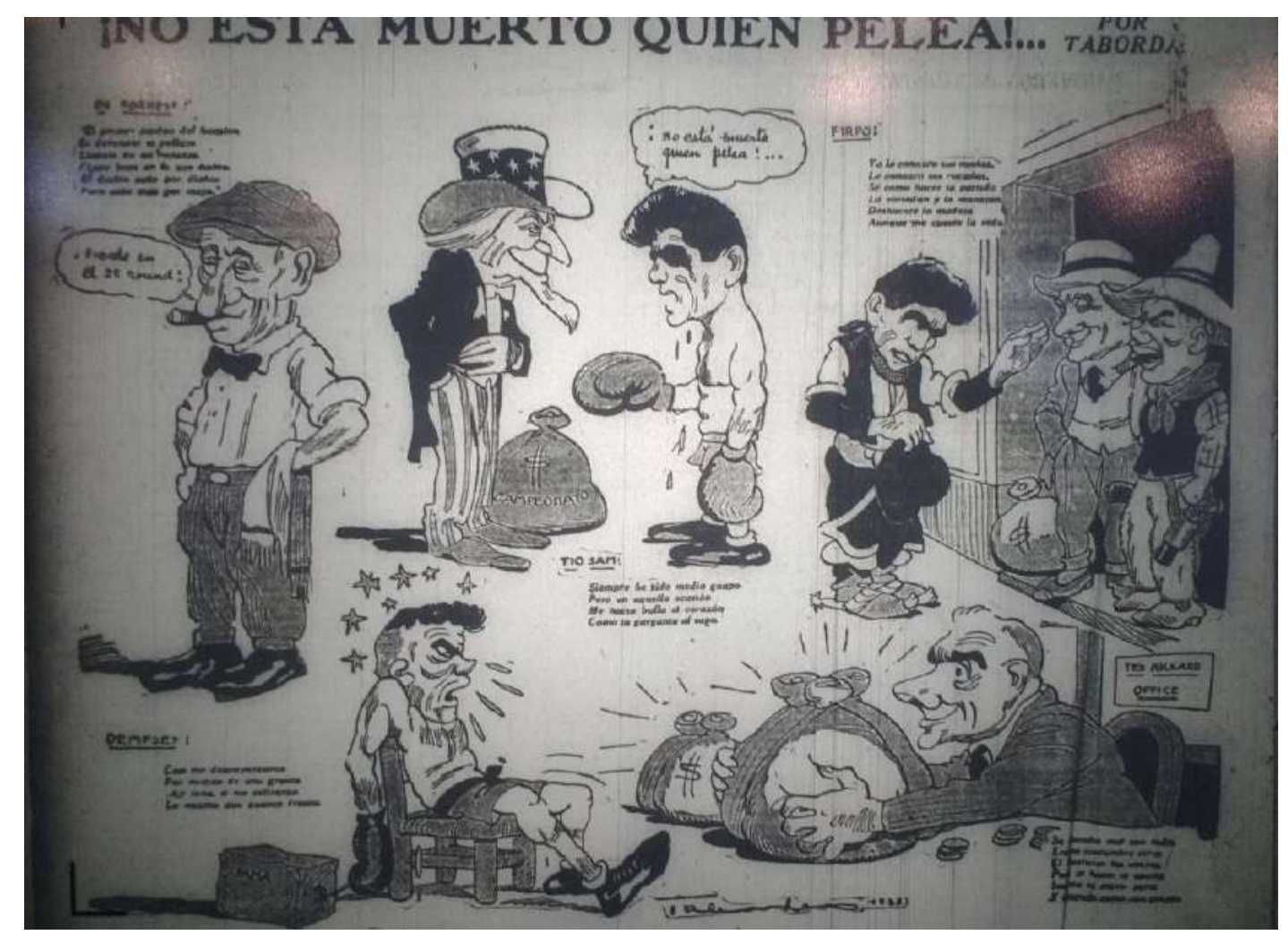

Imagen 8. Crítica [Buenos Aires], set. 15, 1923: 2

En este sentido, la caricatura «No está muerto quien pelea» (Imagen 8) refleja la disconformidad ante la resolución del match. Si Firpo hubiera ganado o si Dempsey hubiera peleado como un verdadero caballero sin ningún tipo de ventajas proporcionadas por el árbitro local o por los fauls cometidos a su favor o por las ayudas recibidas por el organizador de las peleas de boxeo Tex Rickard. Pero principalmente Crítica pensaba que Firpo hubiera ganado sin los engaños y artimañas de Tex Rickard, «el zorro del ring».34 Si bien son afirmativas todas las acusaciones de trampa y engaños que Crítica y otros medios de comunicación le atribuyen a Jack Dempsey y a Tex Rickard, también es cierto que Firpo no tenía los «conocimientos científicos»35 ni la

que vencido parecía vencedor, porque los que caen luchando, nunca besan la tierra humillante» (Crítica [Buenos Aires], set. 15, 1923: 3); «Firpo ha sido sacrificado» (Crítica [Buenos Aires], set. 16, 1923: 4).

${ }^{32}$ Crítica [Buenos Aires], set. 16, 1923: 8.

${ }^{33}$ Crítica [Buenos Aires], set. 17, 1923: 2.

${ }^{34}$ Crítica [Buenos Aires], set. 15, 1923: 3.

35 «Firpo no tiene la ciencia pugilística ni la agilidad de Dempsey» Crítica [Buenos Aires], set. 7, $1923: 15$. 
escuela pugilística de Dempsey ${ }^{36}$ y que tampoco estaba preparado física, técnica y tácticamente para dicha pelea. La carrera boxística de Firpo, en comparación con la de Dempsey, era mucho más corta y con menor cantidad de títulos obtenidos. Tampoco contaba con entrenamientos específicos y planificados, ya que a Firpo le gustaba entrenarse solo y con pocos asesoramientos deportivos y nutricionales. En este sentido, la derrota de Firpo pudo ser atribuida a diversos aspectos, pero un determinado sector de la prensa escrita argentina, especialmente Crítica, no logró aceptarla. Estas negaciones o justificaciones irrisorias se debían al hecho de que su derrota provocaba un debilitamiento de los sentidos y representaciones transmitidos a través del evento deportivo.

\section{Consideraciones finales}

Los medios de comunicación como la prensa escrita argentina junto con los deportes en general, y el boxeo en particular, brindan un nuevo espacio público de espectáculo y de consumo. Un espacio que permite el despliegue de diversas lógicas discursivas en torno al cuerpo, el género y la sexualidad, la sanidad física, intelectual y moral y los grupos identitarios y étnicos. En este caso en particular, a través del carácter performativos de las imágenes, comprendidas dentro de estas a las fotografías, dibujos y caricaturas, lograron producir, representar y potenciar ciertos sentidos y representaciones sobre una masculinidad popular y nacionalidad argentina y, en menor medida, estadounidense. Una masculinidad popular argentina con características físicas, intelectuales y morales como la valentía, la fuerza, la resistencia, la honradez, lo pasional e instintivo y lo indisciplinado, que aportaba a la configuración nacional de la tríada criollo-gaucho-argentino. Dichas características también delimitaron en algunos puntos los sentidos y las representaciones en torno al concepto de raza latina. Este concepto de raza toma mayor sentido en un contexto argentino y latinoamericano con las características de la década del veinte, cuando las preocupaciones por el stock biológico de la nación y los discursos médicos y eugenésicos tomaron centralidad en la opinión pública y en las políticas estatales. En contraposición, se puede identificar un intento de cierta parte de la prensa escrita argentina de atribuirle ciertas características físicas, intelectuales y morales a la

\footnotetext{
36 «La pelea del viernes ha servido para demostrar en forma hasta elocuente, la pobreza de los conocimientos boxísticos de nuestro campeón y su inexperiencia absoluta de las tretas del ring. [...] Es lento y algo torpe» Crítica [Buenos Aires], set. 16, 1923: 9.
} 
masculinidad estadounidense. Estas características son la fuerza, la cobardía, la eficiencia, el raciocinio, el disciplinamiento, la frialdad, el engaño y el cientificismo. A diferencia de la identificación de la tríada criollo-gaucho-argentino, no se puede identificar este tipo de relación con respecto a los estereotipos estadounidense. Sin embargo, se puede identificar una relación directa entre la masculinidad y la nacionalidad estadounidense, que constituyeron y representaron a la raza sajona.

Para finalizar, Crítica, a diferencia de los demás periódicos y revistas analizados, supo utilizar las caricaturas como mecanismo constructor y potenciador de ciertos sentidos y representaciones. A través de ellas desplegaron una lógica discursiva e iconográfica irónica, sensacionalista, coloquial y humorística, logrando condensar de manera exitosa una serie de discursos, sentidos y representaciones en torno al género y a la sexualidad, a la moral, al cuerpo, a la raza y a la nacionalidad argentina y, en menor medida, estadounidense. Estas lógicas identitarias y estos estereotipos normativos se enmarcan en una lógica binaria, característica de la modernidad, que intenta delimitar lo propio y lo ajeno, lo nacional y lo extranjero para construir y legitimar una mismidad con su consecuente otredad.»

\section{Obras citadas}

\subsection{Fuentes primarias}

Caras y Caretas (1923)

Crítica [Buenos Aires, 1923]

Fray Mocho (1923)

La Época [Buenos Aires, 1923]

La Vanguardia [Buenos Aires, 1923]

\subsection{Bibliografia}

Alabarces, Pablo. Fútbol y patria: el fútbol y las narrativas de la nación en la Argentina. Buenos Aires: Prometeo, 2002.

Archetti, Eduardo P. El potrero, la pista y el ring: las patrias del deporte argentino. Vol. 593. Buenos Aires: Fondo de Cultura Económica, 2001.

Archetti, Eduardo P. «El deporte en Argentina (1914-1983)». Trabajo y sociedad 6.7 (2005): 1-30.

Arfuch, Leonor. «Ver el mundo con otros ojos. Poderes y paradojas de la imagen en la sociedad global». Leonor Arfuch y Verónica Devalle (Comps.). Visualidades sin fin, Imagen y diseño en la sociedad global. Buenos Aires: Prometeo (2009): 1540 . 
Armus, Diego. «La ciudad impura: salud, tuberculosis y cultura en Buenos Aires, 18701950 ". La ciudad impura: salud, tuberculosis y cultura en Buenos Aires, 18701950. 2007. 416-416.

Barrancos, Dora, Donna J. Guy, y Adriana María Valobra, eds. Moralidades y comportamientos sexuales: Argentina, 1880-2011. Buenos Aires: Biblos, 2014.

Bertolotto, Antonella. «La pelea del siglo xx; prensa, masculinidad y nacionalidad». History of Education in Latin America-HistELA 3 (2020): e21431-e21431.

Bonetto, María Julia. «El uso de la Fotografía en la investigación social». Revista Latinoamericana de Metodología de la Investigación Social. ReLMIS 11 (2016): 71-83.

Bontempo, María Paula. «Editorial Atlántida: un continente de publicaciones, 19181936». (2012).

Bourdieu, Pierre. La dominación masculina. Madrid: Editorial Popular (2000).

De Diego, José Luis. Editores y políticas editoriales en Argentina, 188o-20oo. Buenos Aires: Fondo de Cultura Económica, 2006

Delgado, Verónica, and Geraldine Rogers. «Tiempos de papel: Publicaciones periódicas argentinas (siglos XIX-XX)». La Plata: Universidad Nacional de La Plata, Estudios/Investigaciones; 60 (2016).

Guiamet, Javier. «Imagen impresa en La Vanguardia en la década de 1920». (2016). Tiempos de papel: Publicaciones periódicas argentinas. Eds. Verónica Delgado y Geraldine Rogers. La Plata: Universidad Nacional de La Plata, Facultad de Humanidades y Ciencias de la Educación. (Estudios/Investigaciones; 60). En Memoria Académica Disponible en: http://www.memoria.fahce.unlp.edu.ar/libros/pm.488/pm.488.pdf, 2016.

Kircher, Mirta. «La prensa escrita: actor social y político, espacio de producción cultural y fuente de información histórica». Revista de Historia. 10 (2005): 115122.

Miranda, Marisa. "La Argentina en el escenario eugénico internacional». Una historia de la eugenesia. Argentina y las redes biopolíticas internacionales (1912-1945). Buenos Aires: Biblos (2012): 19-64.

Mosse, George L. La imagen del hombre: La creación de la masculinidad moderna. Prensa de la Universidad de Oxford, 1998.

Nari, Marcela MA. Políticas de maternidad y maternalismo político: Buenos Aires, 1890-1940. Buenos Aires: Biblos, 2004.

Palla, Jonathan Daniel. «Bitácora de Willie Farrell. Pugilismo, escenarios y negocios a ambos lados del Atlántico. (1920-1960)». Claves. Revista de Historia 4.7 (2018): 59-88.

Qués, María Elena. Medios y política: imágenes, discursos y sentidos. Buenos Aires, Editorial Universitaria Rioplatense, 2013.

Rocchi, Fernando. «A la vanguardia de la modernización: la incipiente formación de un campo publicitario en la Argentina durante la década de 1920». Estudios Interdisciplinarios de América Latina y el Caribe 27.2 (2016): 47-76.

Rogers, Geraldine. Caras y Caretas. La Plata: Universidad Nacional de La Plata, 2008. 
Saítta, Sylvia. Regueros de tinta. El diario Critica en la década de 1920. Buenos Aires: Sudamericana, 1998. 316.

Sarlo, Beatriz. Buenos Aires 1920 y 1930. Una modernidad periférica. Buenos Aires: Nueva Visión (1988).

Scharagrodsky, Pablo Ariel. «Las peleas económico-comerciales más allá del boxeo. Prensa, avisos publicitarios y radio en Argentina en los años '20». Pensar la publicidad. Revista internacional de investigaciones publicitarias 14 (2020): 89-103.

Scharagrodsky, Pablo Ariel. «La prensa y la "pelea del siglo”: Luis Ángel Firpo vs. Jack Dempsey. Argentinidad, latinidad y virilidad en los años '20 ». Hombres en movimiento. Ed. Pablo Ariel Scharagrodsky. Buenos Aires: Prometeo, 2021.

Shirkin, Susana. «El trabajo extranjero en los escenarios de Buenos Aires a través de Caras y Caretas y Fray Mocho (1900-1920)». Telondefondo. Revista de Teoría y Crítica Teatral 31 (2020).

Szir, Sandra M. El semanario popular ilustrado Caras y Caretas y las transformaciones del paisaje cultural de la modernidad Buenos Aires 18981908. Buenos Aires, Facultad de Filosofía y Letras, Universidad de Buenos Aires (2016). 